OPEN ACCESS

Edited by: Umair Akram

Jiangsu University, China

Reviewed by:

Zubair Akram,

Beijing Institute of Technology, China

Muhammad Kaleem Khan,

East China Jiaotong University, China

*Correspondence:

Syed Hussain Mustafa Gillani hussainmustafagillani@gmail.com

Specialty section:

This article was submitted to

Organizational Psychology,

a section of the journal

Frontiers in Psychology

Received: 03 November 2021

Accepted: 20 December 2021

Published: 17 January 2022

Citation:

Jamil K, Dunnan L, Gul RF,

Shehzad MU, Gillani SHM and

Awan FH (2022) Role of Social Media

Marketing Activities in Influencing

Customer Intentions: A Perspective of

a New Emerging Era.

Front. Psychol. 12:808525.

doi: 10.3389/fpsyg.2021.808525

\section{Role of Social Media Marketing Activities in Influencing Customer Intentions: A Perspective of a New Emerging Era}

\author{
Khalid Jamil', Liu Dunnan', Rana Faizan Gul', Muhammad Usman Shehzad², \\ Syed Hussain Mustafa Gillani ${ }^{3 *}$ and Fazal Hussain Awan ${ }^{1}$ \\ 'School of Economics and Management, North China Electric Power University, Beijing, China, ${ }^{2}$ Department \\ of Management Sciences and Engineering, Zhengzhou University, Zhengzhou, China, ${ }^{3}$ Faisalabad Business School, \\ National Textile University, Faisalabad, Pakistan
}

The aim of this study is to explore social media marketing activities (SMMAs) and their impact on consumer intentions (continuance, participate, and purchase). This study also analyzes the mediating roles of social identification and satisfaction. The participants in this study were experienced users of two social media platforms Facebook and Instagram in Pakistan. A self-administered questionnaire was used to collect data from respondents. We used an online community to invite Facebook and Instagram users to complete the questionnaire in the designated online questionnaire system. Data were collected from 353 respondents, and structural equation modeling (SEM) was used to analyze the data. Results show that SMMAs have a significant impact on the intentions of users. Furthermore, social identification mediates the relationship between social media activities and satisfaction, and satisfaction mediates the relationship between social media activities and the intentions of users. This will help marketers how to attract customers to develop their intentions. This is the first novel study that used SMMAs to address the user intentions with the role of social identification and satisfaction in the context of Pakistan.

Keywords: social media marketing activities, social identification, satisfaction, continuance intention, participate intention, purchase intention

\section{INTRODUCTION}

There has been tremendous growth in the use of social media platforms such as WhatsApp, Instagram, and Facebook over the past decade (Chen and Qasim, 2021). People are using these platforms to communicate with one another, and popular brands use them to market their products. Social activities have been brought from the real world to the virtual world courtesy of social networking sites. Messages are sent in real time which now enable people to interact and share information. As a result, companies consider social media platforms as vital tools for succeeding in the online marketplace (Ebrahim, 2020). The use of social media to commercially promote processes or events to attract potential consumers online is referred to as social media marketing (SMM). With the immense rise in community websites, a lot of organizations have started to find the best ways to utilize these sites in creating strong relationships 
and communications with users to enable friendly and close relationships to create online brand communities (Ibrahim and Aljarah, 2018).

Social media marketing efficiently fosters communications between customers and marketers, besides enabling activities that enhance brand awareness (Hafez, 2021). For that reason, SMM remains to be considered as a new marketing strategy, but how it impacts intentions is limited. But, to date, a lot of research on SMM is focused on consumer's behavior, creative strategies, content analysis and the benefits of user-generated content, and their relevance to creating virtual brand communities (Ibrahim, 2021).

New channels of communication have been created, and there have been tremendous changes in how people interact because of the internet developing various applications and tools over time (Tarsakoo and Charoensukmongkol, 2020). Companies now appreciate that sharing brand information and consumer's experience is a new avenue for brand marketing due to the widespread use of smartphones and the internet, with most people now relying on social media brands. Therefore, developing online communities has become very efficient. Social groups create a sense of continuity for their members without meeting physically (Yadav and Rahman, 2017). A community that acquires products from a certain brand is referred to as a virtual brand community. Customers are not just interested in buying goods and services but also in creating worthwhile experiences and strong relationships with other customers and professionals. So, when customers are part of online communities, there is a cohesion that grows among the customers, which impacts the market. Therefore, it is up to the companies to identify methods or factors that will encourage customers to take part in these communities (Ismail et al., 2018).

The online community's nature is like that of actual communities when it comes to creating shared experiences, enabling social support, and attending to the members' need to identify themselves, regardless of the similarities and variances existing between real-world communities and online communities (Seo and Park, 2018). Regarding manifestations and technology, online communities are distinct from reallife communities since the former primarily use computers to facilitate their operation. A certain brand product or service is used to set up a brand community. Brand communities refer to certain communities founded based on interactions that are not limited by geographical restrictions between brand consumers (Chen and Lin, 2019). Since consumers' social relationships create brand communities, these communities have customs, traditions, rituals, and community awareness. The group members learn from each other and share knowledge about a product, hence appreciating each other's actions and ideas. So, once a consumer joins a particular brand community, automatically, the brand becomes a conduit and common language linking the community members together because of sharing brand experiences (Arora and Sanni, 2019).

Based on the perspective of brand owners, most research has focused on how social communities can benefit brands. However, there are also some discussions regarding the benefits that come from brand community members according to the members themselves to analyze how social community impacts its members (Shareef et al., 2019). Consumer's behavior is influenced by value so, when a consumer is constantly receiving value, it leads to consumer's loyalty toward that brand. According to Alalwan et al. (2017), a valuable service provider will create loyalty to a company and enhance brand awareness. Consumer value is essentially used in evaluating social networking sites. With better and easier options to create websites coming around, most consumers are attracted to a social community to know about a company and its goods. Furthermore, operators can learn consumer's behavior through maintaining social interactions with customers. However, the social community should have great value. It should be beneficial to the potential customers by providing them with information relevant to the brand in question. Furthermore, customers should be able to interact with one another, thus creating a sense of belonging. From that, it is evident that a brand social community's satisfaction affects community retention and selection.

\section{LITERATURE REVIEW}

\section{Social Media Marketing Activities}

Most businesses use online marketing strategies such as blogger endorsements, advertising on social media sites, and managing content generated by users to build brand awareness among consumers (Wang and Kim, 2017). Social media is made up of internet-associated applications anchored on technological and ideological Web 2.0 principles, which enables the production and sharing of the content generated by users. Due to its interactive characteristics that enable knowledge sharing, collaborative, and participatory activities available to a larger community than in media formats such as radio, TV, and print, social media is considered the most vital communication channel for spreading brand information. Social media comprises blogs, internet forums, consumer's review sites, social networking websites (Twitter, Blogger, LinkedIn, and Facebook), and Wikis (Arrigo, 2018).

Social media facilitates content sharing, collaborations, and interactions. These social media platforms and applications exist in various forms such as social bookmarking, rating, video, pictures, podcasts, wikis, microblogging, social blogs, and weblogs. Social networkers, governmental organizations, and business firms are using social media to communicate, with its use increasing tremendously (Cheung et al., 2021). Governmental organizations and business firms use social media for marketing and advertising. Integrated marketing activities can be performed with less cost and effort due to the seamless interactions and communication among consumer partners, events, media, digital services, and retailers via social media (Tafesse and Wien, 2018).

According to Liu et al. (2021), marketing campaigns for luxury brands consist of main factors such as customization, reputation, trendiness, interaction, and entertainment which significantly impact customers' purchase intentions and brand equity. Activities that involve community marketing accrue from interactions between events and the mental states of individuals, whereas products are external factors for 
users (Parsons and Lepkowska-White, 2018). But even though regardless of people experience similar service activities, there is a likelihood of having different ideas and feelings about an event; hence, outcomes for users and consumers are distinct. In future marketing, competition will focus more on brand marketing activities; hence, the marketing activities ought to offer sensory stimulation and themes that give customers a great experience. Now brands must provide quality features but also focus on enabling an impressive customer's experience (Beig and Khan, 2018).

\section{Social Identification}

A lot of studies about brand communities involve social identification, appreciating the fact that a member of a grand community is part and parcel of that community. Social identity demystifies how a person enhances self-affirmation and selfesteem using comparison, identity, and categorization (Chen and Lin, 2019). There is no clear definition of the brand community or the brand owner, strengthening interactions between the community and its members or creating a rapport between the brand and community members. As a result, members of a community are separated into groups based on their educational attainment, occupation, and living environment. Members of social networks categorize each other into various groups or similar groups according to their classification in social networks (Salem and Salem, 2021).

Brand identification and identification of brand communities emanate from a similar process. Users can interact freely, hence creating similar ideologies about the community, alongside strengthening bonds among members, hence enabling them to identify with that community. The brand community identity can also be considered as a convergence of values between the principles of the social community and the values of the users (Wibowo et al., 2021).

According to Lee et al. (2021), members of a brand social community share their ideas by taking part in community activities to help create solutions. When customers join a brand community, they happily take part in activities or discussions and are ready to help each other. So, it is evident that social community participation is impacting community identity positively. Community involvement entails a person sharing professional understanding or knowledge with other members to enhance personal growth and create a sense of belonging (Gupta and Syed, 2021). According to Haobin Ye et al. (2021), it is high time community identity be incorporated in virtual communities since it is a crucial factor that affects the operations of virtual communities. Also, community identity assists in facilitating positive interactions among members of the community, encouraging them to actively take part in community activities (Assimakopoulos et al., 2017). This literature review suggests that social communities need members to work together. Individuals who can identify organizational visions and goals become dedicated to that virtual company.

\section{Satisfaction}

Customer's satisfaction involves comparing expected and after-service satisfaction with the standards emanating from accumulated previous experiences. According to implementation confirmation theory, satisfaction is a consumer's expected satisfaction with how the services have lived up to those expectations. Customers usually determine the level of satisfaction by comparing the satisfaction previously experienced and the current one (Pang, 2021).

According to recent studies, community satisfaction impacts consumer's loyalty and community participation. A study community's level of satisfaction is determined by how its members rate it (Jarman et al., 2021). Based on previous interactions, the community may be evaluated. When the members are satisfied with their communities, it is manifested through joyful emotions, which affect the behavior of community members. In short, satisfaction creates active participation and community loyalty (Shujaat et al., 2021).

\section{Types of Intentions}

A lot of studies about information and marketing systems have used continuance intention in measuring if a customer continues to use a certain product or service. The willingness of customers to continue using a good or service determines if service providers will be successful or not. According to Zollo et al. (2020), an efficient information marketing system should persuade users to use it, besides retaining previous users to guarantee continued use.

Operators of social networks must identify the reason propelling continued use of social network sites, alongside attracting more users. Nevertheless, previous studies on information systems in the last two decades have mainly concentrated on behavior-cognition approaches, for instance, the technology acceptance model (TAM), theory of planned behavior (TPB), and theory of reasoned action (TRA) with their variants (Tarsakoo and Charoensukmongkol, 2020; Jamil et al., 2021b). According to Ismail et al. (2018), perceived use and satisfaction positively impact a user's continuance intention. The continued community members' participation has two intentions. Continuance intention is the first one. It defines the community member's intent to keep on using the community (Beig and Khan, 2018; Dunnan et al., 2020). Then, recommendation intention, also known as mouth marketing, describes every informal communication that takes place among community members regarding the virtual brand community. Previous studies about members of a virtual community mostly entailed the continuous utilization of information systems (Seo and Park, 2018; Sarfraz et al., 2021). Unlike previous studies, this study focuses on factors that support the continued participation of community members. So, besides determining how usage purpose affects continuance intention, the study also investigated the factors that influence users' willingness to take part in community activities (Gul et al., 2021).

Nevertheless, it is hard to determine and monitor whether a certain action occurred (recommendation or purchase) during empirical investigations. Consumers will seek relevant information associated with their external environment and experiences when purchasing goods (Shareef et al., 2019). Once they have collected significant information, they will evaluate it, and draw comparisons from which customer's 
behavior is determined. Since purchase intention refers to a customer's affinity toward a particular product, it is a metric of a customer's behavioral intention. According to Liu et al. (2021), the probability of a customer buying a particular product is known as an intention to buy. So, when the probability is high, it simply means that the willingness to purchase is high. Past studies consider purchase intention as a factor that can predict consumer's behavior alongside the subjective possibility of consumer's purchases. According to Chen and Qasim (2021), from a marketing viewpoint, if a company wants to retain its community besides achieving community targets while establishing successful marketing via the community, at least three objectives are needed. They include membership continuance intention, which entails members living up to their promises in the community and also the willingness to belong to the community (Yadav and Rahman, 2018; Naseem et al., 2020). On the other side, community recommendation intention entails the willingness of members to recommend or refer community members to other people who are not members (Jamil et al., 2021a; Mohsin et al., 2021). The next consideration is the community participation intention of a member, which involves their willingness to participate in the activities of the brand community. Unlike past literature about using information systems, this study demystified how SMMAs influence purchase intention and participation intention (Alalwan et al., 2017).

\section{Development of Hypotheses}

People with similar interests can get a virtual platform to discuss and share ideas courtesy of social media. Sustained communication of social media allows users to create a community. Long-lasting sharing of growth and information fosters the development of strong social relationships. The information posted on social media platforms by an individual positively correlates with the followers the user has. Regarding the discussion above, we proposed the following hypothesis:

H1: Social media marketing activities (SMMAs) have a significant impact on social identification.

The study of Farivar and Richardson (2021) on users' continuance intention confirmed that it is influenced by satisfaction after service. Social media studies are also of the thought that satisfaction significantly affects continuance intention. So, a consumer will measure the satisfaction of service after using it. Mahendra (2021) claims that satisfaction influences repurchase behavior. Repurchase intention emanates from a customer's satisfaction with a good or service. People who have similar interests may interact and cooperate in a virtual world via social media platforms. A community on social media may be formed by regularly connecting with people and exchanging information with them. Members benefit from long-term information and growth exchanges that enable them to create strong social relationships. A lot of studies have pointed out that repurchase intention and customer's satisfaction are positively and highly related. Besides, marketing studies noted that satisfactory experience after using a product would impact the intention of future repurchase. Hence, we proposed the following hypothesis:

\section{$\mathrm{H}$ 2: SMMAs have a significant impact on satisfaction.}

The study by Suman et al. (2021) on American consumer's behavior suggested that members taking part in community activities (meetups, discussion, and browsing) influence their brand-associated behavior. According to Di Minin et al. (2021), the brand identity of a consumer has a positive impact on satisfaction. Consumers capitalize on online communities to share their experiences and thoughts about a grand regularly and easily (Sirola et al., 2021). These experiences make up the customer to brand experiences and establish a sense of belonging, trust, and group identity. In a nutshell, this study suggests that identity will enable members to recognize their community, hence confirming that members have similar experiences and feelings with a particular brand and feel united in the group (Shujaat et al., 2021). Strong group identity means that members are integrated closely into the brand communities and highly regard the community. Hence, we proposed the following hypothesis:

H3: Social identification has a significant impact on satisfaction.

Brand communities are beneficial in the sense that they enable sharing of marketing information, managing a community, and exploring demands (Dutot, 2020). These activities are likely to enhance consumer's rights and increase customer's satisfaction (Sahibzada et al., 2020). A customer who makes an online transaction will be highly satisfied with a website that provides a great experience (Koçak et al., 2021). Enhancing customer's satisfaction, encouraging customer intentions, creating community loyalty, and fostering communication and interactions between community users are crucial to lasting community platform management (Pang, 2021). Hence, we proposed the following hypotheses:

$\begin{array}{rlrrr}\text { H4: Satisfaction has a } & \text { significant impact } & \text { on } \\ & \text { continuance intention. } & & \\ \text { H5: Satisfaction has a significant impact on } & \text { participate intention. } \\ \text { H6: Satisfaction has a significant impact on purchase intention. }\end{array}$

Thaler (1985) proposed transaction utility theory, in which consumers' willingness to spend money is influenced by their perceptions of value. Researchers such as Dodds (1991) claimed that buyers only become ready to purchase after they have established a sense of value for a product. According to Petrick et al. (2001), a product's quality is dependent on the customer's satisfaction. Several studies have shown that enjoyment, perceived value, and behavioral intention are all linked together. Hence, we proposed the following hypothesis:

H7: Social identification mediates the relationship between SMMA and satisfaction.

When it comes to information systems, Bhattacherjee et al. (2008) discovered that people's continual intention is derived from their satisfaction with the system after they have used it. Studies on employee's satisfaction in the workplace have shown that it has a substantial influence on CI. The amount of satisfaction that users 
have with the system that they have previously used is the most important factor in determining their $\mathrm{CI}$, according to research on information system utilization intention.

In other words, the customer's contentment with the product leads to the establishment of a desire to buy the thing again, as mentioned by Assimakopoulos et al. (2017). Numerous studies show a strong link between customer's satisfaction and their propensity to return for another transaction. According to a lot of marketing studies, customers who have a pleasant experience with a product are more likely to repurchase it. Hence, we proposed the following hypotheses:

H8: Satisfaction mediates the relationship between social identification and continuance intention.

H9: Satisfaction mediates the relationship between social identification and participate intention.

H10: Satisfaction mediates the relationship between social identification and purchase intention.

Figure 1 shows the research framework of this study.

\section{CONCEPTUAL FRAMEWORK}

\section{Research Methodology}

This study designed a questionnaire according to the hypotheses stated above. The participants in this study were experienced users of two social media platforms Facebook and Instagram in Pakistan. A self-administered questionnaire was used to collect data from respondents. A pilot study with 40 participants was carried out. Since providing recommendations, revisions were made to the final questionnaire to make it more understandable for the study's respondents. To ensure the content validity of the measures, three academic experts of marketing analyzed and make improvements in the items of constructs. The experts searched for spelling errors and grammatical errors and ensured that the items were correct. The experts have proposed minor text revisions to social identification and satisfaction items and advised that the original number of items is to be maintained.
This study used an online community to invite Facebook and Instagram users to complete the questionnaire in the designated online questionnaire system. Online questionnaires have the following advantages (Tan and Teo, 2000): (1) sampling is not restricted to a single geological location, (2) lower cost, and (3) faster questionnaire responses. A total of 353 questionnaires were returned from respondents. There were 353 appropriate replies considered for the final analysis.

\section{Measures}

The study used items established from prior research to confirm the reliability and validity of the measures. All items are evaluated through 5-point Likert-type scales where "1" (strongly disagree), “3” (neutral), and “5” (strongly agree).

\section{Dependent Variable}

To get a response about three dimensions of intention (continuance, participate, and purchase), we used eight items adopted from prior studies;

1. Continuance intention is measured by three items from the study of Bhattacherjee et al. (2008), and the sample item is, "I intend to continue buying social media rather than discontinue its use."

2. Participate intention is evaluated by three items from the work of Debatin et al. (2009), and the sample item is, "my intentions are to continue participating in the social media activities."

3. Purchase intention was determined by two items adapted from the work of Pavlou et al. (2007), and the sample item is, "I intend to buy using social media in the near future."

\section{Independent Variable}

To analyze the five dimensions of SMMAs, we used eleven items adopted from a prior study of Kim and Ko (2012).

1. Entertainment is determined by two items and the sample item is, "using social media for shopping is fun."

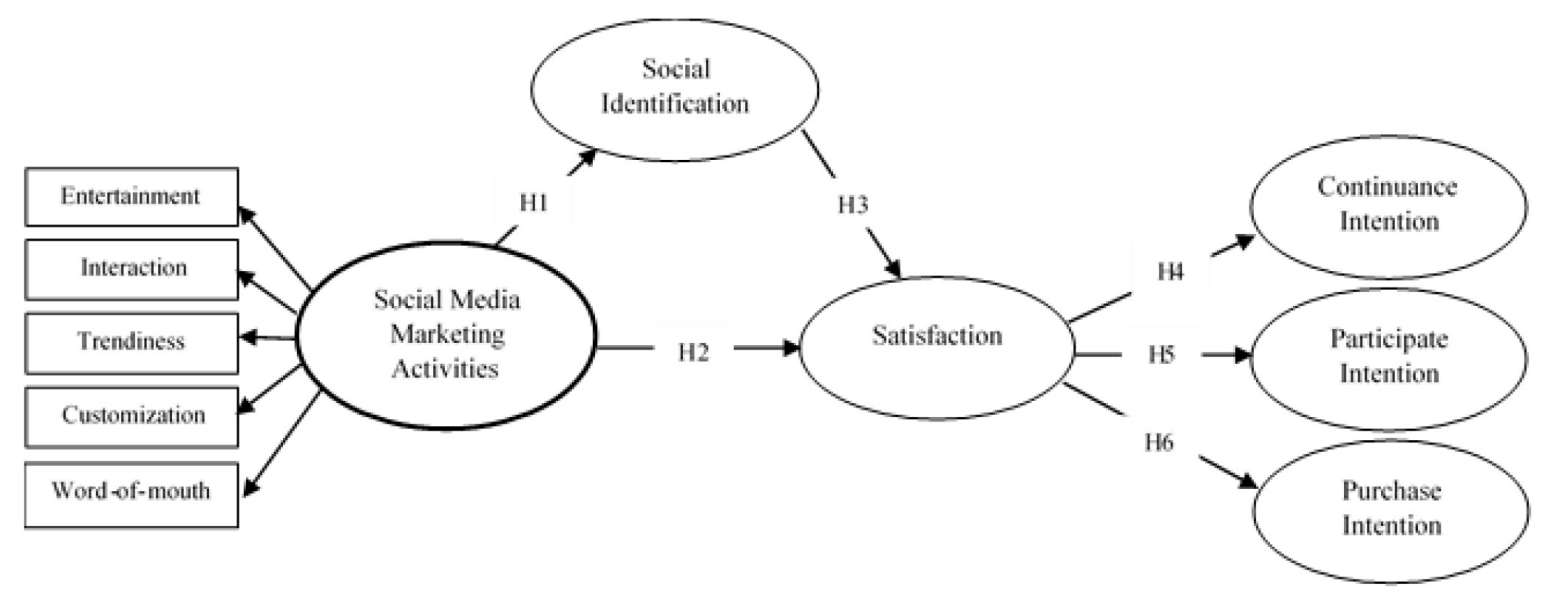

FIGURE 1 | Conceptual framework. 
TABLE 1 | Inner model evaluation.

\begin{tabular}{|c|c|c|c|c|c|}
\hline Variables & & Item loading & AVE & CR & $\alpha$ \\
\hline \multirow[t]{3}{*}{ Continuance intention } & $\mathrm{Cl} 1$ & 0.887 & 0.794 & 0.880 & 0.712 \\
\hline & $\mathrm{Cl} 2$ & 0.756 & & & \\
\hline & $\mathrm{Cl} 3$ & 0.881 & & & \\
\hline \multirow[t]{4}{*}{ Customization } & Cust1 & 0.759 & 0.652 & 0.851 & 0.741 \\
\hline & Cust2 & 0.878 & & & \\
\hline & Cust3 & 0.679 & & & \\
\hline & Cust4 & 0.844 & & & \\
\hline \multirow[t]{4}{*}{ Entertainment } & E1 & 0.781 & 0.687 & 0.865 & 0.762 \\
\hline & E2 & 0.884 & & & \\
\hline & E3 & 0.719 & & & \\
\hline & E4 & 0.861 & & & \\
\hline \multirow[t]{6}{*}{ Interaction } & Int1 & 0.840 & 0.753 & 0.859 & 0.671 \\
\hline & $\ln 2$ & 0.762 & & & \\
\hline & $\ln 3$ & 0.756 & & & \\
\hline & $\ln 4$ & 0.724 & & & \\
\hline & $\ln 5$ & 0.858 & & & \\
\hline & $\ln 6$ & 0.799 & & & \\
\hline \multirow[t]{3}{*}{ Participant intention } & $\mathrm{Pl1}$ & 0.872 & 0.894 & 0.934 & 0.825 \\
\hline & $\mathrm{Pl} 2$ & 0.940 & & & \\
\hline & $\mathrm{Pl} 3$ & 0.913 & & & \\
\hline \multirow[t]{2}{*}{ Purchase intention } & Pul1 & 0.896 & 0.652 & 0.850 & 0.739 \\
\hline & Pul2 & 0.822 & & & \\
\hline \multirow[t]{5}{*}{ Social identification } & Sl1 & 0.775 & 0.907 & 0.929 & 0.685 \\
\hline & $\mathrm{SI} 2$ & 0.815 & & & \\
\hline & $\mathrm{SI} 3$ & 0.772 & & & \\
\hline & $\mathrm{SI} 4$ & 0.828 & & & \\
\hline & $\mathrm{SI} 5$ & 0.819 & & & \\
\hline \multirow[t]{6}{*}{ Satisfaction } & Satis1 & 0.861 & 0.862 & 0.900 & 0.643 \\
\hline & Satis2 & 0.778 & & & \\
\hline & Satis3 & 0.807 & & & \\
\hline & Satis4 & 0.874 & & & \\
\hline & Satis5 & 0.833 & & & \\
\hline & Satis6 & 0.808 & & & \\
\hline \multirow[t]{4}{*}{ Trendiness } & Trn1 & 0.852 & 0.900 & 0.952 & 0.909 \\
\hline & Trn2 & 0.955 & & & \\
\hline & Trn3 & 0.822 & & & \\
\hline & Trn4 & 0.952 & & & \\
\hline \multirow[t]{4}{*}{ Word of mouth } & WOM1 & 0.767 & 0.685 & 0.864 & 0.760 \\
\hline & WOM2 & 0.868 & & & \\
\hline & WOM3 & 0.788 & & & \\
\hline & WOM4 & 0.876 & & & \\
\hline
\end{tabular}

2. Interaction is evaluated by three items, and the sample item is, "conversation or opinion exchange with others is possible through brand pages on social media."

3. Trendiness is measured by two items, and the sample item is, "contents shown in social media is the newest information."

4. Customization is measured by two items, and the sample item is, "brand's pages on social media offers customized information search."

5. Word of mouth is measured by two items, and the sample item is, "I would like to pass along information on the brand, product, or services from social media to my friends."

\section{Mediating Variables}

We used two mediating variables in this study,

1. Social identification was measured with five items adopted from the prior study of Bhattacharya and Sen (2003), and the sample item is, "I see myself as a part of the social media community."

2. Satisfaction was evaluated with six items adopted from the study of Chen et al. (2015), and the sample item is, "overall, I am happy to purchase my desired product from social media."

\section{RESULTS}

This research employs a partial least square (PLS) modeling technique, instead of other covariance-based approaches such as LISREL and AMOS. The reason behind why we pick PLSSEM is that it is most suitable for confirmatory and also exploratory research (Hair Joe et al., 2016). Structural equation modeling (SEM) has two approaches, namely covariance-based and PLS-SEM (Hair et al., 2014). PLS is primarily used to validate hypotheses, whereas SEM is most advantageous in hypothesis expansion (Podsakoff et al., 2012). A PLS-SEM-based methodology would be done in two phases, first weighing and then measurement (Sarstedt et al., 2014). PLS-SEM is ideal for a multiple-order, multivariable model. To do small data analysis is equally useful in PLS-SEM (Hair et al., 2014). PLS-SEM allows it easy to calculate all parameter calculations (Hair Joe et al., 2016). The present analysis was conducted using SmartPLS 3.9.

\section{Model Measurement}

Table 1 shows this study model based on 31 items of the seven variables. The reliability of this study model is measured with Cronbach's alpha (Hair Joe et al., 2016). As shown in Table 1, all items' reliability is robust, Cronbach's alpha $(\alpha)$ is greater than 0.7. Moreover, composite reliability (CR) fluctuates from.80 to.854, which surpassed the prescribed limit of 0.70 , affirming that all loadings used for this research have shown up to satisfactory indicator reliability. Ultimately, all item's loadings are over the 0.6 cutoff, which meets the threshold (Henseler et al., 2015).

The Cronbach's alpha value for all constructs must be greater than 0.70 is acceptable (Hair et al., 2014). All the values of $\alpha$ are greater than 0.7 as shown in Table $\mathbf{1}$ and Figure 2.

Convergent validity is measured by $\mathrm{CR}$ and AVE, and scale reliability for each item (Hair Joe et al., 2016). The scholar says that CR and AVE should be greater than 0.7 and 0.5 , respectively. By utilizing CR and average variance extracted scores, convergent validity was estimated (Fornell and Larcker, 1981). As elaborated in Table 3, the average variance extracted scores of all the indicators are greater than 0.50 and CR is higher than.70 which is elaborating an acceptable threshold of convergent validity and internal consistency. It is stated that a value of CR, that is, not less than 0.70, is acceptable and evaluated as a good indicator 


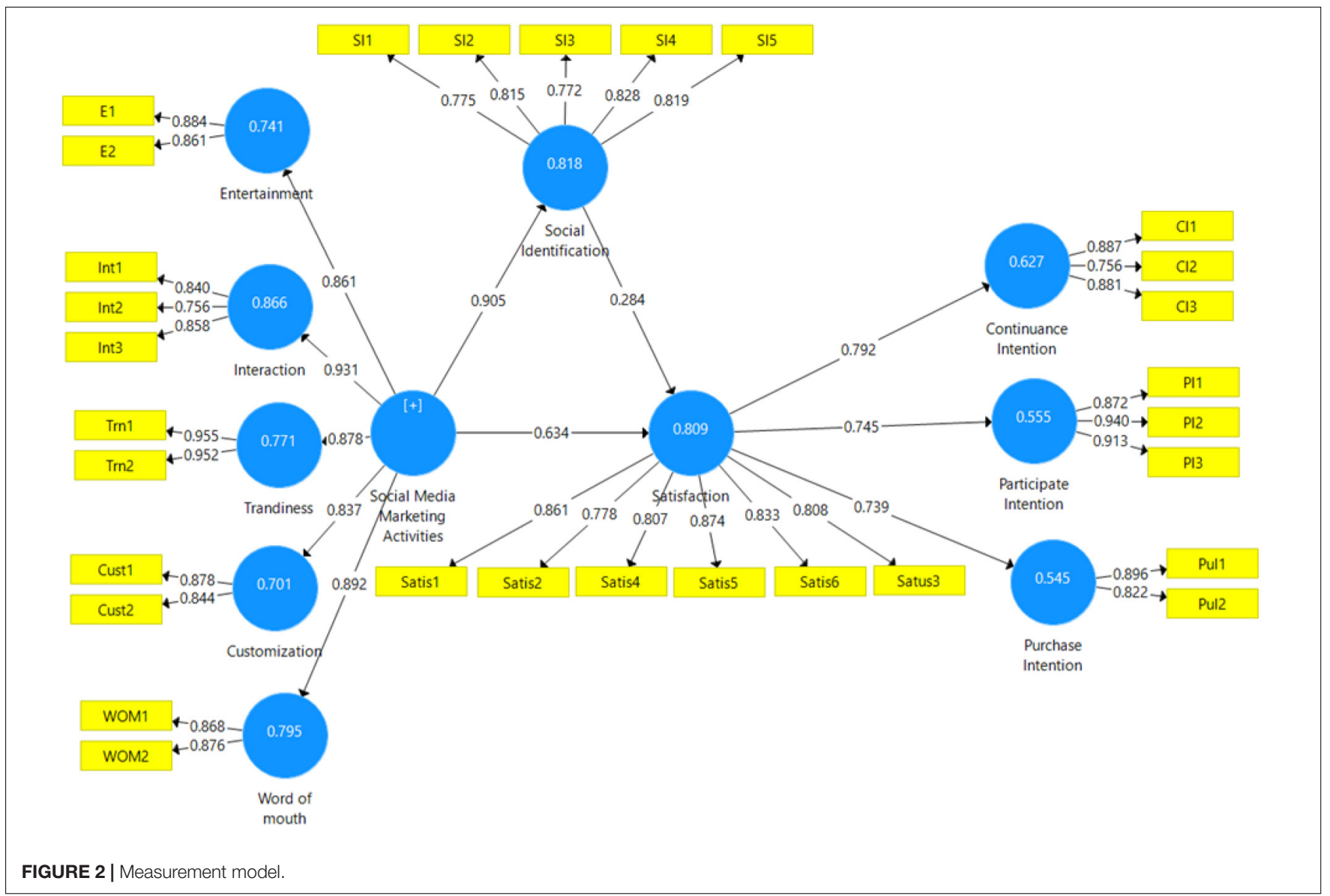

TABLE 2 | A mediation analysis.

\begin{tabular}{|c|c|c|c|c|c|}
\hline Hypotheses & Direct effect & Indirect effect & Total Effect & VIF & Decision \\
\hline SI- > SAT- > PAI & $\begin{array}{c}\mathrm{B}=0.324, t \text {-value }=5.324, \\
p=0.000\end{array}$ & $\begin{array}{c}\mathrm{B}=0.211, t \text {-value }=4.338 \\
p=0.000\end{array}$ & $\begin{array}{c}\mathrm{B}=0.439, t \text {-value }=4.345 \\
p=0.000\end{array}$ & $73 \%$ & Supported \\
\hline
\end{tabular}

TABLE 3 | Discriminant validity.

\begin{tabular}{|c|c|c|c|c|c|c|c|c|c|c|c|c|c|}
\hline \multicolumn{7}{|c|}{ Fornell-Larcker criterion } & \multicolumn{7}{|c|}{ Heterotrait-monotrait (HTMT) ratios } \\
\hline & Cl & PI & PUI & Sat & SI & SMMA & & Cl & PI & PUI & Sat & SI & SMMA \\
\hline $\mathrm{Pl}$ & 0.682 & 0.908 & & & & & $\mathrm{PI}$ & 0.854 & 0.873 & & & & \\
\hline PUI & 0.622 & 0.714 & 0.860 & & & & PUI & 0.765 & 0.825 & 0.789 & & & \\
\hline Sat & 0.792 & 0.745 & 0.739 & 0.827 & & & Sat & 0.847 & 0.869 & 0.786 & 0.876 & & \\
\hline SMMA & 0.823 & 0.879 & 0.839 & 0.821 & 0.605 & 0.770 & SMMA & 0.759 & 0.769 & 0.945 & 0.804 & 0.846 & 0.876 \\
\hline
\end{tabular}

Cl, continuance intention; PI, participate intention; PUI, purchase intention; Sat, satisfaction; SI, social identification; SMMA, social media marketing activities. 
of internal consistency (Sarstedt et al., 2014). Moreover, average variance extracted scores of more than 0.50 demonstrate an acceptable convergent validity, as this implies that a specific construct with greater than $50 \%$ variations is clarified by the required indicators.

This study determines the discriminant validity through two techniques named Fornell-Larcker criterion and heterotraitmonotrait (HTMT) (Hair Joe et al., 2016). In line with Fornell and Larcker (1981), the upper right-side diagonal values should be greater than the correlation with other variables, which is the square root of AVE, which indicates the discriminant validity of the model. Table 3 states that discriminant validity was developed top value of variable correlation with itself is highest. The HTMT ratios must be less than 0.85 , although values in the range of 0.90 to 0.95 are appropriate (Hair Joe et al., 2016). Table 3 displays that all HTMT ratios are less than 0.90, which reinforces the statement that discriminant validity was supported in this study's classification.

To determine the problem of multicollinearity in the model, VIF was calculated for this purpose. The experts said that if the value of VIF is greater than 5, there is no collinearity issue in findings (Hair et al., 2014). The results indicate that the inner value of VIF for all indicators must fall in the range of 1.421 to 1.893. Furthermore, these study findings show no issue of collinearity with data, and the study has stable results.

To evaluate "the explanatory power of the model," the $R^{2}$ value was analyzed for every predicted variable. It shows the degree to which independent variables illustrate the dependent variables. $R^{2}$ value in "between 0 and 1 with higher values shows a higher level of predictive accuracy. Subsequent values of $R^{2}$ describe 0.25 for weak, 0.50 for moderate, and 0.75 for" substantial. An appropriate model is indicated by $R^{2}$ greater than 0.5 in primary results. In Figure 2, the value of $R^{2}$ greater than 0.5 on all exogenous constructs, which also means that the model has strong predictive accuracy (Hair Joe et al., 2016).

Table 4 displays the percentage of variance clarified for every variable: $62.7 \%$ of continuous intention, $55.5 \%$ of participate intention, $54.5 \%$ for purchase intention, $80.9 \%$ for satisfaction, and $81.8 \%$ for social identification. In general, results demonstrate that values of $R^{2}$ of endogenous variables are greater than $80 \%$, which is the sign of a substantial "parsimonious model" (Sarstedt et al., 2014). Most importantly, the outputs give a significant validation of the model. $Q^{2}$ values of all four 5 latent variables suggest that the model is extremely predictive (Hair et al., 2014).

\section{Hypothesis Testing}

This study evaluates the significance of relationships using bootstrapping at 5,000 with a replacement sample (Hair Joe et al., 2016; Awan et al., 2021). The findings show that SMMAs have significant relationship with social identification $(\beta=0.905, t$-value $=36.570, p=0.000)$ which accept the H1. The findings show that SMM significantly influences the satisfaction $(\beta=0.634, t$-value $=8.477, p=0.000)$. Social identification has significant positive relationship with satisfaction as shown in
TABLE 4 | Predictive accuracy and relevance of the model.

\begin{tabular}{lcc}
\hline Construct & $\mathbf{R}$-square $\mathbf{( R}^{\mathbf{2}} \mathbf{~}$ & $\mathbf{( Q}^{\mathbf{2}} \mathbf{~}$ \\
\hline Continuance intention & 0.627 & 0.430 \\
Participate intention & 0.555 & 0.452 \\
Purchase intention & 0.545 & 0.395 \\
Satisfaction & 0.809 & 0.544 \\
Social identification & 0.818 & 0.512 \\
\hline
\end{tabular}

Table $5(\beta=0.284, t$-value $=4.348, p=0.000)$ which accept the $\mathrm{H} 3$. The results show that satisfaction has significant relationship with continuous intention $(\beta=0.792, t$-value $=15.513, p=0.000)$ which support the H4. The findings show that satisfaction has strong positive relationship with participant intention $(\beta=0.745$, $t$-value $=12.041, p=0.000)$, which support the H5. The findings show that satisfaction has strong positive relationship with purchase intention $(\beta=0.739, t$-value $=12.397, p=0.000)$ which support the H6. The findings of the current investigation support $\mathrm{H} 1, \mathrm{H} 2, \mathrm{H} 3, \mathrm{H} 4, \mathrm{H} 5$, and $\mathrm{H} 6$. The results show that H4, H1a, $\mathrm{H} 1 \mathrm{~b}, \mathrm{H} 3 \mathrm{a}, \mathrm{H} 3 \mathrm{~b}, \mathrm{H} 2 \mathrm{a}$, and $\mathrm{H} 2 \mathrm{~b}$ are accepted (refer to Table 5 and Figure 3).

Preacher and Hayes (2008) argue that if the VIF value is greater than $80 \%$, then it shows full mediation, and value of VIF equal to 20 to $80 \%$ which indicate the partial mediation and if VIF falls below 20\%, then there is no mediation. The findings show that social identification mediates the relationship between SMM and satisfaction $(\beta=0.213, t$-value $=3.570$, $p$-value $=0.000)$ and indirect effect $(\beta=0.257, t$-value $=4.481$, $p$-value $=0.000)$ with variance accounted for (VAF) $75 \%$ which show partial mediation. In this, the VAF describes the size of the indirect effect in relation to the total effect (Hayes and Preacher, 2010). The findings show that satisfaction mediates the relationship between social identification and continuous intention $(\beta=0.342, t$-value $=3.435, p$-value $=0.000)$ and indirect effect $(\beta=0.225, t$-value $=4.636, p$-value $=0.000)$ with VAF $64 \%$ which show partial mediation. In this, the VAF describes the size of the indirect effect in relation to the total effect (Hayes, 2009). The findings show that satisfaction mediates the relationship between social identification and participant intention $(\beta=0.324, t$-value $=5.325, p$-value $=0.000)$ and indirect effect $(\beta=0.211, t$-value $=4.338, p$-value $=0.000)$ with VAF $73 \%$ which show partial mediation. The findings show that satisfaction mediates the relationship between social identification and purchase intention $(\beta=0.312$, $t$-value $=3.434$, $p$-value $=0.000)$ and indirect effect $(\beta=0.3 .213, t$-value $=5.437$, $p$-value $=0.000)$ with VAF $78 \%$ which show partial mediation (refer to Table 2).

\section{DISCUSSION AND CONCLUSION}

The study was about SMMAs as proposed by Kim and Ko (2012), and it investigated which factors influence social media usage. The findings of the study include the following:

Most studies about social websites have not exhausted the impact of SMMAs. According to this study, SMMAs 


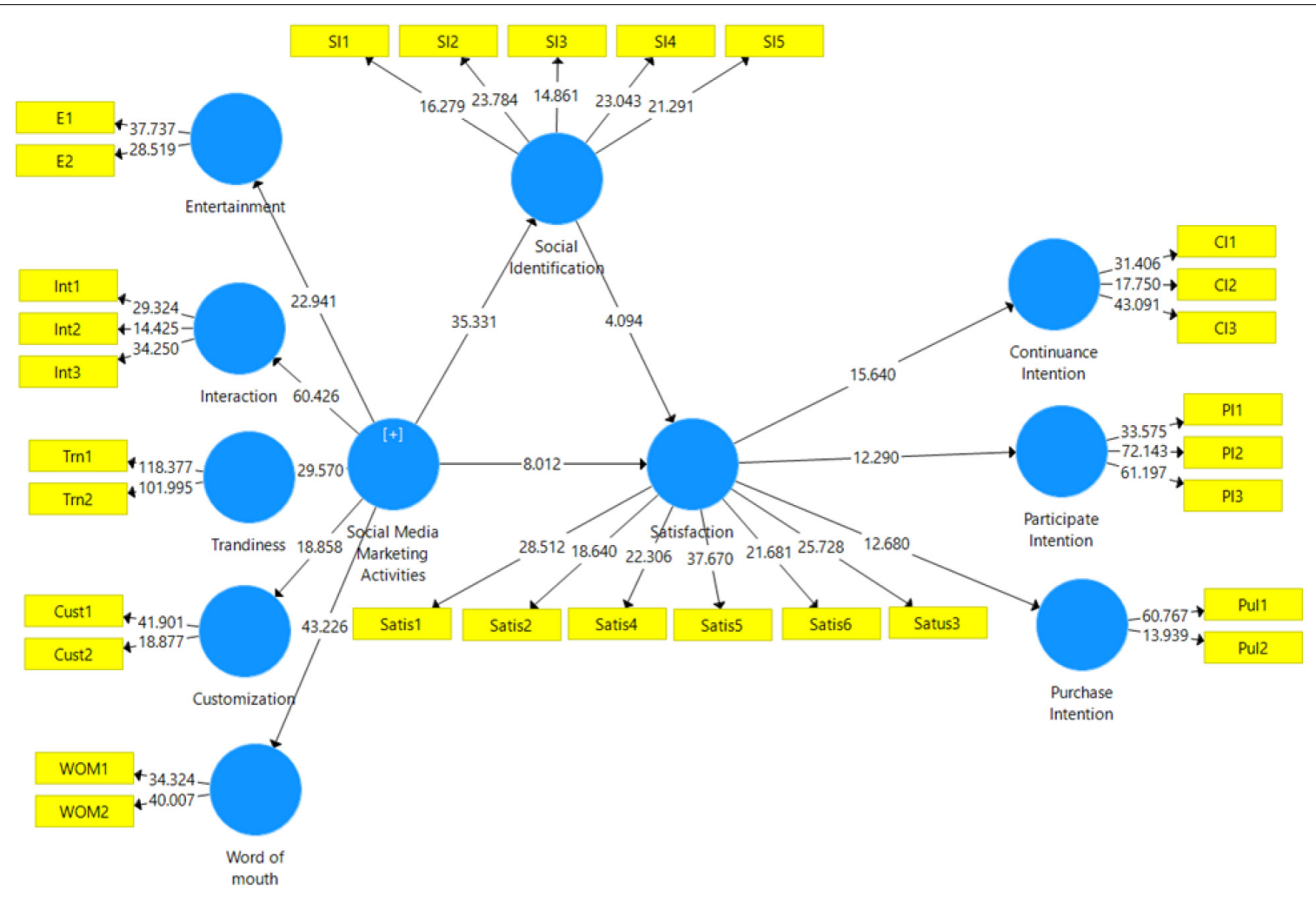

FIGURE 3 | Structural model.

TABLE 5 | Hypothesis testing

\begin{tabular}{|c|c|c|c|c|c|c|}
\hline & Hypothesis & Path coefficient ( $t$-value) & Confidence interval & $F$ square & $p$-values & Decision \\
\hline $\mathrm{H} 1$ & SMMA - > SI & $0.905(36.570)$ & 0.838 to 0.937 & 4.507 & 0.000 & Accepted \\
\hline $\mathrm{H} 2$ & SMMA - > Sat & $0.634(8.477)$ & 0.443 to 0.789 & 0.383 & 0.000 & Accepted \\
\hline $\mathrm{H} 4$ & Sat - > Cl & $0.792(15.513)$ & 0.791 to 0.872 & 1.678 & 0.000 & Accepted \\
\hline $\mathrm{H} 5$ & Sat - > Pl & $0.745(12.041)$ & 0.596 to 0.835 & 1.246 & 0.000 & Accepted \\
\hline $\mathrm{H} 6$ & Sat - > PUI & 0.739 (12.397) & 0.593 to 0.824 & 1.200 & 0.000 & Accepted \\
\hline
\end{tabular}

significantly affect social identification, which ultimately influences purchase decisions, participation decisions, continuance intention, and satisfaction. The study demystified social media usage intention. The findings were that SMMAs could sustain corporate brands. According to Beig and Khan (2018), unlike blog marketing and keyword advertising that were associated with content, SMM gets to the targeted audiences to enhance the impact of the information being shared by creating strong relationships in the online community. Therefore, service providers of social media must put into consideration means of increasing the impact of SMMAs. To boost SMMAs, operators should increase activity on the forum. The members of a community can be allowed to explain the guiding factors behind choosing a particular brand over that of competitors for other members to know the competing brands. From the discussions and sharing of knowledge, members get an opportunity to understand why they like a particular brand, thus enhancing brand loyalty and community cohesion (Yadav and Rahman, 2017).

The study also confirmed that most administrators are concerned with the influence of brand community management in creating business advantage. According to Tarsakoo and Charoensukmongkol (2020), marketing strategies and tools have undergone tremendous changes since the inception of social media. Consumers no longer must rely on traditional media to acquire information about a product before making their purchase since social media can effectively and easily avail such information. For that reason, social media service providers must come up with effective measures of controlling publication timing, frequency, and content to achieve the set marketing targets. According to this study, if a company can successfully assist users to easily identify with a particular brand community, strong relationships will be fostered between the consumers and the brand, hence creating customer's loyalty (Ebrahim, 2020). Besides, users may stop using competitors' products. 
So, companies need to appreciate that proper management of online strategies and brand community in creating community identity enhances brand's competitiveness and inspires members of the brand community to shun using goods and services from competitors.

\section{Limitations and Recommendations}

Regardless of the efforts geared toward enabling in-depth data collection, research methodology, and research structure, there were still various limitations that ought to be dealt with in studies to be conducted in the future. For instance, using online questionnaires in data collection, some members might have been very willing to fill them because of their community identity, hence enabling self-selection bias that may impact the validity and authenticity of the outcomes. Besides, a crosssectional sample was used in the study; hence, results from the analysis can only demystify individual usage patterns on wellknown social media. Nevertheless, the different social media platforms provide different services; hence, long-term usage needs long-term observation. The outcomes of growth model analysis with the experimental values and browsing experiences of users at the various phases in longitudinal studies to be conducted in the future may be increasingly conclusive on casual relationships with variables. The third limitation of the study is that different countries or areas have different preferences regarding social media. Future studies should unravel the

\section{REFERENCES}

Alalwan, A. A., Rana, N. P., Dwivedi, Y. K., and Algharabat, R. (2017). Social media in marketing: A review and analysis of the existing literature. Telem. Inform. 34, 1177-1190. doi: 10.1016/j.tele.2017.05.008

Arora, A. S., and Sanni, S. A. (2019). Ten years of 'social media marketing'research in the Journal of Promotion Management: Research synthesis, emerging themes, and new directions. J. Promot. Manag. 25, 476-499. doi: 10.1080/ 10496491.2018.1448322

Arrigo, E. (2018). Social media marketing in luxury brands. Manag. Res. Rev. 41, 657-679. doi: 10.1108/MRR-04-2017-0134

Assimakopoulos, C., Antoniadis, I., Kayas, O. G., and Dvizac, D. (2017). Effective social media marketing strategy: Facebook as an opportunity for universities. International J. Retail Distribut. Manag. 45, 532-549. doi: 10.1108/IJRDM-112016-0211

Awan, F. H., Dunnan, L., Jamil, K., Gul, R. F., Guangyu, Q., and Idrees, M. (2021). Impact of Role Conflict on Intention to leave Job with the moderating role of Job Embeddedness in Banking sector employees. Front. Psychol. 12:719449. doi: 10.3389/fpsyg.2021.719449

Beig, F. A., and Khan, M. F. (2018). Impact of social media marketing on brand experience: A study of select apparel brands on Facebook. Vision 22, 264-275. doi: 10.1177/0972262918785962

Bhattacharya, C. B., and Sen, S. (2003). Consumer-company identification: A framework for understanding consumers' relationships with companies. J. Marke. 67, 76-88. doi: 10.1509/jmkg.67.2.76.1 8609

Bhattacherjee, A., Perols, J., and Sanford, C. (2008). Information technology continuance: A theoretic extension and empirical test. J. Comput. Inform. Systems 49, 17-26.

Chen, S. C., and Lin, C. P. (2019). Understanding the effect of social media marketing activities: The mediation of social identification, perceived value, and satisfaction. Technol. Forecast. Soc. Change 140, 22-32. doi: 10.1016/j.techfore. 2018.11.025

Chen, X., and Qasim, H. (2021). Does E-Brand experience matter in the consumer market? Explaining the impact of social media marketing activities reasons behind individuals from various cultural backgrounds or countries using different social media platforms and what might be the demands and motivations behind their preferences. Besides, new social networking sites such as Facebook and Twitter have unique characteristics which are different from traditional sites. Future studies should also focus on this shift. For this study, the emphasis was on SMMAs' influence on user's behavior and usage demands.

\section{DATA AVAILABILITY STATEMENT}

The raw data supporting the conclusion of this article will be made available by the authors, without undue reservation.

\section{AUTHOR CONTRIBUTIONS}

All authors listed have made a substantial, direct, and intellectual contribution to the work, and approved it for publication.

\section{FUNDING}

This study was partly supported by the National Social Science Foundation of China (no. 19ZDA081).

on consumer-based brand equity and love. J. Consumer Behav. 20, 1065-1077. doi: 10.1002/cb.1915

Chen, Y.-S., Lin, C.-Y., and Weng, C.-S. (2015). The influence of environmental friendliness on green trust: The mediation effects of green satisfaction and green perceived quality. Sustainability 7, 10135-10152.

Cheung, M. L., Pires, G. D., Rosenberger, P. J. III, Leung, W. K. S., and Ting, H. (2021). Investigating the role of social media marketing on value co-creation and engagement: An empirical study in China and Hong Kong. Austral. Marke. J. 29, 118-131. doi: 10.1016/j.ausmj.2020.03.006

Debatin, B., Lovejoy, J. P., Horn, A.-K., and Hughes, B. N. (2009). Facebook and online privacy: Attitudes, behaviors, and unintended consequences. J. Comput. Med. Commun. 15, 83-108.

Di Minin, E., Fink, C., Hausmann, A., Kremer, J., and Kulkarni, R. (2021). How to address data privacy concerns when using social media data in conservation science. Conservat. Biol. 35, 437-446. doi: 10.1111/cobi.13708

Dodds, W. B. (1991). In search of value: how price and store name information influence buyers' product perceptions. J. Consumer Marke. 8, 15-24. doi: 10. 1108/07363769110034974

Dunnan, L., Jamil, K., Abrar, U., Arain, B., Guangyu, Q., and Awan, F. H. (2020). "Analyzing the green technology market focus on environmental performance in Pakistan," in 2020 3rd International Conference on Computing, Mathematics and Engineering Technologies (ICoMET) (Sukkur: IEEE), 1-5. doi: 10.1016/ s1351-4180(08)70002-3

Dutot, V. (2020). A social identity perspective of social media's impact on satisfaction with life. Psychol. Marke. 37, 759-772. doi: 10.1111/j.1547-5069. 2011.01394.x

Ebrahim, R. S. (2020). The role of trust in understanding the impact of social media marketing on brand equity and brand loyalty. J. Relat. Marke. 19, 287-308. doi: 10.1080/15332667.2019.1705742

Farivar, F., and Richardson, J. (2021). Workplace digitalisation and work-nonwork satisfaction: the role of spillover social media. Behav. Inform. Technol. 40, 747-758. doi: 10.1080/0144929x.2020.1723702

Fornell, C., and Larcker, D. F. (1981). Evaluating structural equation models with unobservable variables and measurement error. J. Marke. Res. 18, 39-50. doi: $10.2307 / 3151312$ 
Gul, R. F., Liu, D., Jamil, K., Baig, S. A., Awan, F. H., and Liu, M. (2021). Linkages between market orientation and brand performance with positioning strategies of significant fashion apparels in Pakistan. Fashion Textiles 8, 1-19.

Gupta, M., and Syed, A. A. (2021). Impact of online social media activities on marketing of green products. International J. Organizat. Anal. [Epub online ahead of print]. doi: 10.1108/IJOA-02-2020-2037

Hafez, M. (2021). The impact of social media marketing activities on brand equity in the banking sector in Bangladesh: the mediating role of brand love and brand trust. International J. Bank Marke. 39, 1353-1376. doi: 10.1108/IJBM-02-20210067

Hair, J. F. Jr., Sarstedt, M., Hopkins, L., and Kuppelwieser, V. G. (2014). Partial least squares structural equation modeling (PLS-SEM). Eur. Bus. Rev. 26, 106-121. doi: 10.1108/EBR-10-2013-0128

Hair Joe, J., Sarstedt, M., Matthews, L. M., and Ringle, C. M. (2016). Identifying and treating unobserved heterogeneity with FIMIX-PLS: part I - method. Eur. Bus. Rev. 28, 63-76. doi: 10.1108/EBR-09-2015-0094

Haobin Ye, B., Fong, L. H. N., and Luo, J. M. (2021). Parasocial interaction on tourism companies' social media sites: antecedents and consequences. Curr. Issues Tourism 24, 1093-1108. doi: 10.1080/13683500.2020.1764915

Hayes, A. F. (2009). Beyond Baron and Kenny: Statistical mediation analysis in the new millennium. Commun. Monogr. 76, 408-420. doi: 10.1080/ 03637750903310360

Hayes, A. F., and Preacher, K. J. (2010). Quantifying and testing indirect effects in simple mediation models when the constituent paths are nonlinear. Multiv. Behav. Res. 45, 627-660. doi: 10.1080/00273171.2010.49 8290

Henseler, J., Ringle, C. M., and Sarstedt, M. (2015). A new criterion for assessing discriminant validity in variance-based structural equation modeling. J. Acad. Marke. Sci. 43, 115-135. doi: 10.1007/s11747-014-0403-8

Ibrahim, B. (2021). Social Media Marketing Activities and Brand Loyalty: A Meta-Analysis Examination. J. Promot. Manag. 28, 60-90.

Ibrahim, B., and Aljarah, A. (2018). Dataset of relationships among social media marketing activities, brand loyalty, revisit intention Evidence from the hospitality industry in Northern Cyprus. Data Brief 21, 1823-1828. doi: 10. 1016/j.dib.2018.11.024

Ismail, A. R., Nguyen, B., and Melewar, T. C. (2018). Impact of perceived social media marketing activities on brand and value consciousness: roles of usage, materialism and conspicuous consumption. International J. Internet Marke. Adv. 12, 233-254. doi: 10.1504/ijima.2018.10013343

Jamil, K., Liu, D., Gul, R. F., Hussain, Z., Mohsin, M., Qin, G., et al. (2021b). Do remittance and renewable energy affect $\mathrm{CO} 2$ emissions? An empirical evidence from selected G-20 countries. Energy Environ. [preprint]. doi: 10.1177/ $0958305 X 211029636$

Jamil, K., Hussain, Z., Gul, R. F., Shahzad, M. A., and Zubair, A. (2021a). The effect of consumer self-confidence on information search and share intention. Inform. Discov. Deliv. [Epub online ahead of print]. doi: 10.1108/IDD-12-20200155

Jarman, H. K., Marques, M. D., McLean, S. A., Slater, A., and Paxton, S. J. (2021). Social media, body satisfaction and well-being among adolescents: A mediation model of appearance-ideal internalization and comparison. Body Image 36, 139-148. doi: 10.1016/j.bodyim.2020.11.005

Kim, A. J., and Ko, E. (2012). Do social media marketing activities enhance customer equity? An empirical study of luxury fashion brand. J. Bus. Res. 65, 1480-1486. doi: 10.1016/j.jbusres.2011.10.014

Koçak, O., İlme, E., and Younis, M. Z. (2021). Mediating Role of Satisfaction with Life in the Effect of Self-Esteem and Education on Social Media Addiction in Turkey. Sustainability 13:9097. doi: 10.3390/su13169097

Lee, H.-W., Kim, S., and Liew, J. (2021). Spectator sports as context for examining observers' agreeableness, social identification, and empathy in a high-stakes conflict situation. Psychol. Rep. 124, 1788-1806. doi: 10.1177/ 0033294120948228

Liu, X., Shin, H., and Burns, A. C. (2021). Examining the impact of luxury brand's social media marketing on customer engagement: Using big data analytics and natural language processing. J. Bus. Res. 125, 815-826. doi: 10.1016/j.jbusres. 2019.04.042

Mahendra, P. T. (2021). Improve Customer Satisfaction through Product Innovation in Social Media. Hum. Soc. Sci. 4, 3719-3729. doi: 10.1007/s11356021-14885-4
Mohsin, M., Zhu, Q., Naseem, S., Sarfraz, M., and Ivascu, L. (2021). Mining Industry Impact on Environmental Sustainability, Economic Growth, Social Interaction, and Public Health: An Application of Semi-Quantitative Mathematical Approach. Processes 9:972. doi: 10.3390/pr9060972

Naseem, S., Fu, G. L., Mohsin, M., Aunjam, M. S., Rafiq, M. Z., Jamil, K., et al. (2020). Development of an inexpensive functional textile product by applying accounting cost benefit analysis. Industria Textila 71, 17-22. doi: 10.35530/it. 071.01 .1692

Pang, H. (2021). Identifying associations between mobile social media users' perceived values, attitude, satisfaction, and eWOM engagement: The moderating role of affective factors. Telematics Inform. 59:101561. doi: 10.1016/j.tele.2020.101561

Parsons, A. L., and Lepkowska-White, E. (2018). Social media marketing management: A conceptual framework. J. Internet Commerce 17, 81-95. doi: 10.1080/15332861.2018.1433910

Pavlou, P. A., Liang, H., and Xue, Y. (2007). Understanding and mitigating uncertainty in online exchange relationships: A principal-agent perspective. MIS Quarterly 31, 105-136. doi: 10.2307/25148783

Petrick, J. F., Backman, S. J., Bixler, R., and Norman, W. C. (2001). Analysis of golfer motivations and constraints by experience use history. J. Leisure Res. 33, 56-70. doi: 10.1080/00222216.2001.11949930

Podsakoff, P. M., MacKenzie, S. B., and Podsakoff, N. P. (2012). Sources of method bias in social science research and recommendations on how to control it. Annu. Rev. Psychol. 63, 539-569. doi: 10.1146/annurev-psych-120710-10 0452

Preacher, K. J., and Hayes, A. F. (2008). Asymptotic and resampling strategies for assessing and comparing indirect effects in multiple mediator models. Behav. Res. Methods 40, 879-891. doi: 10.3758/brm.40.3.879

Sahibzada, U. F., Cai, J., Latif, K. F., and Sahibzada, H. F. (2020). Knowledge management processes, knowledge worker satisfaction, and organizational performance. Aslib J. Inform. Manag. 72, 112-129. doi: 10.1108/AJIM-10-20190276

Salem, S. F., and Salem, S. O. (2021). Effects of social media marketing and selected marketing constructs on stages of brand loyalty. Global Bus. Rev. 22, 650-673. doi: 10.1177/0972150919830863

Sarfraz, M., Mohsin, M., Naseem, S., and Kumar, A. (2021). Modeling the relationship between carbon emissions and environmental sustainability during COVID-19: A new evidence from asymmetric ARDL cointegration approach. Environ. Devel. Sustain. 23, 16208-16226. doi: 10.1007/s10668-021-01 324-0

Sarstedt, M., Ringle, C. M., Henseler, J., and Hair, J. F. (2014). On the emancipation of PLS-SEM: A commentary on Rigdon (2012). Long Range Plan. 47, 154-160. doi: 10.1016/j.lrp.2014.02.007

Seo, E.-J., and Park, J.-W. (2018). A study on the effects of social media marketing activities on brand equity and customer response in the airline industry. J. Air Transp. Manag. 66, 36-41. doi: 10.1016/j.jairtraman.2017.09.014

Shareef, M. A., Mukerji, B., Dwivedi, Y. K., Rana, N. P., and Islam, R. (2019). Social media marketing: Comparative effect of advertisement sources. J. Retail. Consum. Ser. 46, 58-69. doi: 10.1016/j.jretconser.2017.11.001

Shujaat, A., Rashid, A., and Muzaffar, A. (2021). Exploring the Effects of Social Media Use on Employee Performance: Role of Commitment and Satisfaction. Pennsylvania: IGI Global, 1788-1809.

Sirola, A., Kaakinen, M., Savolainen, I., Paek, H.-J., Zych, I., and Oksanen, A. (2021). Online identities and social influence in social media gambling exposure: A four-country study on young people. Telematics Inform. 60:101582. doi: 10.1016/j.tele.2021.101582

Suman, C., Chaudhary, R. S., Saha, S., and Bhattacharyya, P. (2021). An attention based multi-modal gender identification system for social media users. Mult. Tools Appl. 1183, 1-23. doi: 10.1109/access.2021.3136552

Tafesse, W., and Wien, A. (2018). Implementing social media marketing strategically: an empirical assessment. J. Marke. Manag. 34, 732-749. doi: 10. 1080/0267257x.2018.1482365

Tan, M., and Teo, T. S. H. (2000). Factors influencing the adoption of Internet banking. J. Assoc. Inform. Syst. 1:5.

Tarsakoo, P., and Charoensukmongkol, P. (2020). Dimensions of social media marketing capabilities and their contribution to business performance of firms in Thailand. J. Asia Bus. Stud. 14, 441-461. doi: 10.1108/JABS-07-20180204 
Thaler, R. (1985). Mental accounting and consumer choice. Marke. Sci. 4, 199-214. doi: $10.1287 / \mathrm{mksc}$.4.3.199

Wang, Z., and Kim, H. G. (2017). Can social media marketing improve customer relationship capabilities and firm performance? Dynamic capability perspective. J. Interact. Marke. 39, 15-26. doi: 10.1016/j.intmar.2017.0 2.004

Wibowo, A., Chen, S.-C., Wiangin, U., Ma, Y., and Ruangkanjanases, A. (2021). Customer behavior as an outcome of social media marketing: The role of social media marketing activity and customer experience. Sustainability 13:189. doi: $10.3390 /$ su13010189

Yadav, M., and Rahman, Z. (2017). Measuring consumer perception of social media marketing activities in e-commerce industry: Scale development \& validation. Telematics Inform. 34, 1294-1307. doi: 10.1016/j.tele.2017.06.001

Yadav, M., and Rahman, Z. (2018). The influence of social media marketing activities on customer loyalty. Benchmarking 25, 3882-3905. doi: 10.1108/BIJ05-2017-0092

Zollo, L., Filieri, R., Rialti, R., and Yoon, S. (2020). Unpacking the relationship between social media marketing and brand equity: The mediating role of consumers' benefits and experience. J. Bus. Res. 117, 256-267. doi: 10.1016/j. jbusres.2020.05.001
Conflict of Interest: The authors declare that the research was conducted in the absence of any commercial or financial relationships that could be construed as a potential conflict of interest.

The reviewer ZA declared a shared affiliation with one of the authors, SG, to the handling editor at time of review.

Publisher's Note: All claims expressed in this article are solely those of the authors and do not necessarily represent those of their affiliated organizations, or those of the publisher, the editors and the reviewers. Any product that may be evaluated in this article, or claim that may be made by its manufacturer, is not guaranteed or endorsed by the publisher.

Copyright (c) 2022 Jamil, Dunnan, Gul, Shehzad, Gillani and Awan. This is an open-access article distributed under the terms of the Creative Commons Attribution License (CC BY). The use, distribution or reproduction in other forums is permitted, provided the original author(s) and the copyright owner(s) are credited and that the original publication in this journal is cited, in accordance with accepted academic practice. No use, distribution or reproduction is permitted which does not comply with these terms. 